\title{
Road traffic accident fatalities (review of 142 post mortem reports)
}

\author{
B. A. KAMDAR \\ G. P. ARDEN \\ M.B., B.S., F.R.C.S. \\ M.B., F.R.C.S.
}

Heatherwood Hospital, Ascot, Berks

\section{Summary}

One hundred and forty-two post mortem reports of road accident deaths in the Windsor accident area have been reviewed. Although head and chest injuries accounted for the deaths of most of these victims, twelve died of inhalation asphyxia and another eighteen died of hypovolaemia due to haemorrhage from otherwise minor injuries. Some of these cases would perhaps have survived if they had received skilled medical attention at the most critical time.

EVERY year 7500 men, women and children die on Britain's roads and many more are seriously injured in road traffic accidents. The estimated resource cost of these accidents in Great Britain in 1970 is valued at $£ 335$ million. The average cost of a fatal accident on the roads of this country is estimated at $£ 19,000$ per accident (Hobbs, 1967; Johnson and Garwood, 1971). There is a far greater loss in human terms.

\section{The analysis}

One hundred and forty-two post mortem reports of road accident fatalities between 1959-1970, who were brought in dead or treated at the Windsor Group of hospitals, have been reveiwed. These hospitals cover an area with a population of 330,000 and the traffic flow through this area includes, among other roads, that carried by the M4, A4, A40 and A30.

Of the 142 fatalities, $79 \%$ were males and $62 \%$ were between the ages of 12-60 years; of these, $28 \%$ were between 12-30 years and 34\% between $30-60$ years; $43.6 \%$ of the victims were brought in dead into the accident departments; $14.8 \%$ died on admission (i.e. within $12 \mathrm{hr}$ of admission) and $41 \cdot 6 \%$ died after admission (12 hr to 30 days) (Fig. 1).

The main cause of death was intracranial haemorrhage in $23.2 \%$ of cases and severe brain damage in $12 \%$ of the cases. Though intracranial haemorrhage was reported in fifty-six fatalities, it directly contributed to death in thirty-three cases. Massive internal haemorrhage $(12.7 \%)$ and severe multiple injuries $(17.6 \%)$ accounted for many other fatalities. However, a significant number died of shock and haemor-

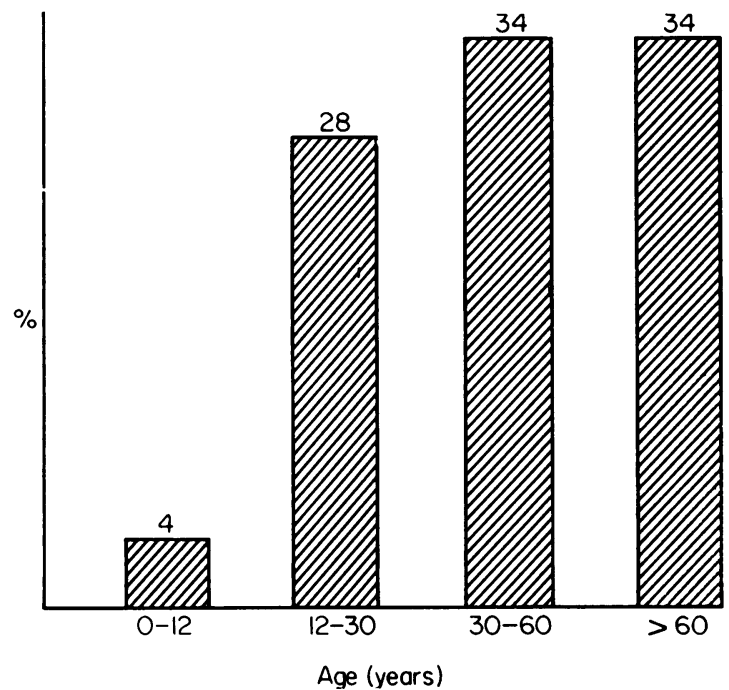

FIg. 1. Age and sex distribution. Male, 79\%; female, $21 \%$.

rhage $(12.7 \%)$ due to relatively 'trivial' injuries, not fatal in themselves. Another significant $8.5 \%$ died of inhalation of blood (Table 1).

Head injuries. These account for $40 \%$ of the fatalities; thirty-three victims out of 142 died of

TABLE 1. Main causes of death

\begin{tabular}{lcc}
\hline \multicolumn{1}{c}{ Main causes of death } & Out of 142 & Per cent \\
\hline Intracranial haemorrhage & 33 & $23 \cdot 2$ \\
Multiple injuries & 25 & $17 \cdot 6$ \\
Shock and haemorrhage & 18 & $12 \cdot 7$ \\
Massive internal haemorrhage & 18 & $12 \cdot 7$ \\
Bronchopneumonia & 17 & $12 \cdot 0$ \\
Severe brain damage & 17 & 12.0 \\
Pulmonary embolism & 12 & $8 \cdot 5$ \\
Inhalation & 12 & $8 \cdot 5$ \\
Chest injuries & 11 & $7 \cdot 7$ \\
Rupture major vessel & 9 & $6 \cdot 3$ \\
Dislocation of cervical spine & 8 & $5 \cdot 6$ \\
Pulmonary oedema & 7 & $4 \cdot 9$ \\
Fat embolism & 4 & $2 \cdot 8$ \\
Gas gangrene and toxaemia & 1 & $0 \cdot 7$ \\
Pelvic abscess and cellulitis & 1 & 0.7 \\
\hline
\end{tabular}


intracranial haemorrhage and seventeen victims had severe brain damage. Cerebral contusion accounted for thirty-four cases; in four cases there was cerebellar damage. Damage to the mid-brain and brain stem always proved fatal (eight cases); cerebral injuries did not always prove to be fatal immediately, although a large proportion of these died subsequently from bronchopneumonia.

Vertebral injuries. Fourteen victims had fractures or dislocations of the vertebral column; of these, eight had transection of the cervical spinal cord and all died.

Chest injuries. In our review we found five out of 142 had a flail segment; thirty had more than three ribs broken on the right side and twenty-one had more than three ribs broken on the left side. In all $35.8 \%$ of the victims had rib fractures. The lung was severely contused in $8.45 \%$ of cases and there was haemothorax in $22.5 \%$ and pneumothorax in $3.5 \%$ of cases. The aorta or subclavian artery was found torn in nine victims and the heart was injured in four victims. All these injuries were fatal.

Abdominal injuries. Abdominal haemorrhage was always large. It was caused by rupture of the liver (eighteen cases), rupture of the spleen (ten cases), rupture of the diaphragm (four cases), intestinal injury (nine cases), ruptured kidney (four cases), and ruptured bladder (three cases).

Fractures of long bones and pelvis. Lower limb fractures were more common than the upper limb fractures. Tibiae were broken in $28.2 \%$ and femora were broken in $26.1 \%$. The right side was the more predominantly injured side. Twenty-four post mortems showed there was a fracture of the pelvis. Supracondylar fractures of the femur and the fracture of the pelvis viz acetabular fractures were not uncommon.

Inhalation. Twelve victims had died of inhalation of blood and asphyxia. Some of these had very trivial injuries. Two illustrative case reports are:-

(1) A man aged 45 years was brought into the casualty department after a road traffic accident. There were lacerations of the upper and lower lip and a scalp wound above the right ear. There was a laceration over the nose and a fracture of the nasal bones. The lacerations were sutured but the man died of asphyxia from inhalation of blood. The post mortem report showed the bronchi filled with blood and mucus and there was severe oedema of the lung. No other post mortem findings were noted.

(2) A male, aged 22 years, was brought in dead. He had been bleeding from the nose and ears. Post mortem findings were fracture of the base of the skull and inhalation asphyxia as the cause of death. No other injuries severe enough to account for death were found.

Shock and haemorrhage. Massive internal haemor-

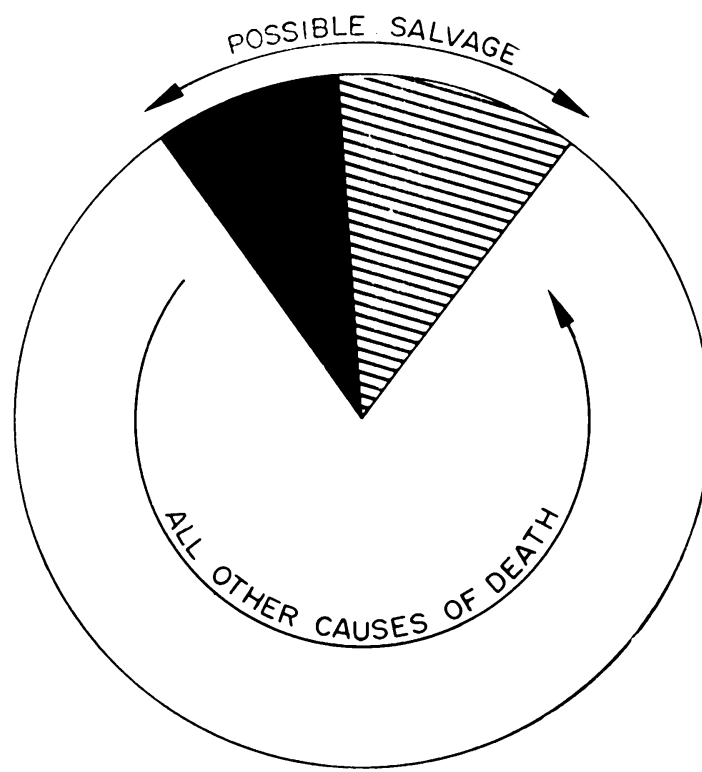

FIG. 2. Possible salvage from inhalation asphyxia ( $\square$, $8.5 \%$ ) and hypovolaemic shock (国, 12.7\%).

rhage was put down as a cause of death in eighteeg $\vec{\varphi}$ victims who could not have survived, even if moke. + efficient resuscitative measures had been commence immediately, as haemorrhage was caused by multipte severe injuries to several vital organs. However, there were eighteen victims $(12.7 \%)$ who had sustained less severe injuries and would have managed to survive if $\frac{\otimes}{\varnothing}$ resuscitation had been carried out earlier. These $\underset{F}{\rightleftharpoons}$ victims were those who had multiple fractures of $\frac{0}{3}$ long bones and several lacerations-but had not sustained injury to a vital organ or a major soft tissue structure. These, in fact, died of hypovolaemia and shock (Fig. 2).

Pulmonary embolism, fat embolism, pulmonary oedema. These were contributory to the cause of 3 . death in those patients who had survived more than $12 \mathrm{hr}$ after the accident. Pulmonary embolism accounted for twelve $(8.5 \%)$ out of 142 cases. This occurred in patients who had lower limb fractures as well as other severe injuries like chest and heado injuries, and had to be nursed in bed for long after the injuries. Four out of 142 died of fat embolism and 0 pulmonary oedema occurred in seven cases. Broncho- $N$ pneumonia was a complication in long term head $\underset{\omega}{N}$ and chest injuries.

Surgical intervention. Tracheostomy was per-formed in fifteen cases, thoracotomy in five cases and $\stackrel{0}{\widetilde{C}}$ nine patients had burr holes to decompress their $\stackrel{\mathbb{Q}}{\rightarrow}$ cranial cavities. Open cardiac massage was done to 0 one case where the patient had a cardiac arrest on $\overline{0}^{\circ}$ the table while undergoing an emergency abdominal ${ }_{\Omega}^{\mathbb{Q}}$ operation. Three patients had abdominal operations $\stackrel{\mathbb{Q}}{\mathbb{Q}}$ 
and four of the 142 cases had their fractures internally fixed.

Medical condition causing accidents. Grattan and Jeffcoate (1968) suggest that chronic disease as a contributory factor to accidents is low $(0.5 \%$ of 593 serious injury accidents). The figure for sudden illness causing minor and serious injury was $1 \cdot 5 / 1000$. In their small series, confined to cases of serious injury, the incidence was $4 / 1000$. In our review, we found that out of 142 fatal accidents, five had a myocardial infarction and one cyclist was known to have fallen off a bicycle during an epileptic fit. The figure of six in 142 cases is indeed very high.

\section{Discussion}

Care of the injured. The need to improve our accident services is of paramount importance. In 1970,7500 people died as a result of road accidents and another 93,500 were seriously injured; slight injuries accounted for 262,353 people-the total figure was 363,353 . Care of the injured, therefore, is a major problem and should have major priority in all the future planning of the National Health Service.

Ruffell Smith (1970b) estimated that the average time lag between the accident and the time when the patient received active treatment is of the order of $15 \mathrm{~min}$ in London and other great towns with equivalent services. An average figure for the whole of Great Britain he puts down at about $20 \mathrm{~min}$. In his review of 374 deaths, nearly half this number occurred in the first $5 \mathrm{~min}$ following the accident; $10 \%$ in the next $10 \mathrm{~min}$; and a further $8 \%$ between 15 and $25 \mathrm{~min}$ after the accident. Therefore, twothirds of deaths, in his series, occurred in the first $25 \mathrm{~min}$. In our review, $43.6 \%$ were brought in dead and $14.8 \%$ died soon after admission (i.e. within $12 \mathrm{hr}$ of admission). The rest $(41.6 \%)$ died between $12 \mathrm{hr}$ and 30 days after admission. Therefore, it is estimated that approximately $58.4 \%$ died within $12 \mathrm{hr}$ of the accident. Ruffell Smith found seventeen cases of inhalation asphyxia in his series of 374 deaths. We have found twelve cases of death by inhalation. In our series, we also had eighteen deaths due to shock and haemorrhage. These were patients with limb haemorrhage, although some with haemothorax, ruptured spleen, fractured pelvis, haemoperitoneum, could have survived if they had been given treatment at the most critical time. Ruffell Smith estimates that there were eleven cases in his series of 374 , i.e. $3 \%$ of all those who died within $12 \mathrm{hr}$, who could have benefited from the treatment being begun between 10 and $20 \mathrm{~min}$. We feel a larger number (thirty in all-twelve cases of inhalation plus eighteen cases of haemorrhage) would have benefited from such treatment and perhaps survived. Moreover, if early treatment is begun, morbidity in cases of seriously injured patients would certainly be lowered.

Frey and colleagues (1969) have reported in their review of 159 road accident deaths, fifteen cases of inhalation asphyxia and fifteen cases of exsanguination-thus thirty cases in all who belonged to the potentially salvageable group. They also reported that a larger percentage of accidents in which salvage was possible occurred during the week rather than at week-ends. Lethal accidents occurred most frequently from 6.00 p.m. to midnight and most infrequently between 6.00 a.m. and noon. Single car accidents accounted for a larger number in the salvageable group.

In his study of deaths and injury on country roads, Adams (1967) suggested that there was a higher mortality rate at the site of the accident outside country towns and higher still on highways outside country towns. The Windsor accident area comprises country towns and fast highways running close to the country towns. In our review $43.6 \%$ died at the site of the accident which closely approximates to the overall figures given by Adams.

The above indicates the need for finding ways and means of improving our rescue services. The need to train our rescue workers in methods of resuscitation can hardly be over-emphasized. Maintenance of a clear airway and replenishment of the lost blood volume in an injured patient should be the most important tasks of the rescue team.

On an average, our rescue services take approximately 20 min to reach the site of the accident from the time of the accident. However, the rescue workers are not competent to start an intravenous drip and pass an endotracheal tube in a severely injured patient. The suggestion that a doctor should go to the site of the accident is open to discussion. In the North Riding of Yorkshire, a service has been organized by $\mathrm{Dr} \mathrm{K}$. Easton, whereby a doctor is always called out to the site of a severe road traffic accident. This service is manned by the local General Practitioners and provides an excellent service in an area where distances are too great between local hospitals and the existing highways.

\section{References}

Adams, A.I. (1967) Death and injury on country roads: a study of 816 persons involved in rural traffic accidents. The Medical Journal of Australia, 2, 799.

Frey, C.F., Huelke, D.F. \& Gikas, P.W. (1969) Resuscitation and survival in motor vehicle accidents. Journal of Trauma, 9, 292.

Gissane, W., Bull, J. \& Roberts, B. (1970) Sequelae of road injuries. A review of one year's admissions to an Accident Hospital. Injury, 1, 195.

Grattan, E., Clegg, N.G. \& Hobbs, J.A. (1970) Chest injuries in unrestrained vehicle occupants who survived a road accident. Road Research Laboratory Report LR, 320. 
Grattan, E. \& JefFcoate, G.O. (1968) Medical factors and road accidents. British Medical Journal, 1, 75.

Grattan, E. \& HoBBS, J.A. (1967) Injuries to the hip joint in vehicle occupants. Road Research Laboratory Report $L R$, 126.

Grattan, E. \& Hobbs, J.A. (1968) Mechanisms of serious lower limb injuries to motor vehicle occupants. Road Research Laboratory Report LR, 201.

Grattan, E., Clegg, N.G. \& HobBS, J.A. (1969) Toughened glass windscreen injuries in car occupants. Road Research Laboratory Report LR, 282.

HoвBS, J.A. (1967) The work of the road accident injury group. Road Research Laboratory Report LR, 108.

JoHNSON, H.D. \& GARWOOD, F. (1971) Notes on road accident statistics. Road Research Laboratory Report LR, 394.
LoNDON, P.S. (1970) Helicopters in civilian medical service. Journal of Trauma, 10, 906.

ROBERTSON, J.S. \& TONGE, J.I. (1968) Duration of survival in traffic accident fatalities. The Medical Journal of Australia, 2, 571 .

Ruffell Smith, H.P. (1970a) A study of fatal injuries in vehicle collisions based on Coroners' reports. Road Research Laboratory Report LR, 316.

Ruffell Smith, H.P. (1970b) Time to die from injuries received in road traffic accidents. Injury, $2,99$.

SEVITT, S. (1968) Death after road traffic accidents. Medicine, Science and the Law, 8, 271.

SEvitr, S. (1968) Fatal road accidents, injuries, complications and causes of death in 250 subjects. British Journal of Surgery, 55, 481. 